\title{
Study on Cultural Industries Integration between Xiamen and Taiwan from the Perspective of Culture
}

\author{
Wen Chao Du \\ Tan Kah Kee College Xiamen University \\ Changchou Fujian, 363105
}

\begin{abstract}
In the process of cross-strait exchanges and trade development, how to promote cultural integration between Xiamen and Taiwan through cultural factors has become an urgent issue to be resolved. The paper starts with cultural integration of two places, analyzes challenges and hidden reasons of cultural integration between these two places, and seeks ways and strategies for cultural integration between the two places.
\end{abstract}

Keywords-Culture integration between Xiamen and Taiwan; Strategy

\section{INTRODUCTION}

At present, there are few researches on the integrated development strategy aiming at the perspective of Taiwan Strait culture, and there are many theories about the characteristics of cultural industry integration from the perspective of economics. There are many writings about the fusion of cultural industries abroad. The direction of research is the change of market boundary, the type and development direction of cultural industry convergence. The foreign research on the integration of cultural industry was first developed from the technical perspective. The American scholar Rosenbe RG discovered the diffusion of the same technology to different cultural industries in the study of the evolution of American machine tool culture industry, and defined this phenomenon as "technology fusion" [1].

The domestic scholar Zhou Zhenhua systematically studied the phenomenon and nature of the integration of cultural industry. He believed that "the integration of cultural industry is the contraction or disappearance of the cultural industry boundary which is based on the integration of the digital industry to adapt to the growth of the cultural industry." Li Wuwei studies cultural industry from a cultural perspective, and thinks that the integration of cultural industry can be integrated through the infiltration of cultural resources and cultural management to produce a new growth point of cultural industry. Ma Jian believes that the cultural industry, through the integration of technology, integrates the resources of different cultural industries, improves the quality of the original cultural industry, and strengthens the cooperative relations among the enterprises in the cultural industry.
II. EXISTING PROBLEMS IN THE CURRENT DEVELOPMENT OF THE CULTURAL INTEGRATION BETWEEN XIAMEN AND TAIWAN

\section{A. The mainstream culture of the island should be partial and whole}

Taiwan culture and Xiamen culture come down in one continuous line, both have similarities and similarities. The similarity is that the roots of Xiamen culture are all in the mainland, and Xiamen culture has been developing as a major part of Fujian culture. The development and continuation of Taiwan culture are mostly a result of the dissemination of Xiamen culture and a part of Xiamen culture. After Taiwan has experienced the era of Japanese opera and the confrontation between the two sides of the Taiwan Straits, the people in the island believe that Chinese culture is the basis of Taiwan culture on the basis of no investigation and evidence research. This is a kind of cultural cognition that generalize and replace the whole image with nodes. This kind of cultural cognition has become the most basic obstacle to the integration of culture in Xiamen and Taiwan.

\section{B. Lack of confidence and distrust in cultural exchange between Xiamen and Taiwan}

The culture of Xiamen and Taiwan share the same roots and development. In cultural exchange, they need to be treated with a peacetime mentality. Taiwan culture is restricted by the problem of small area and small population. After decades of development, it gradually fell into a bottleneck. The gradual development of the mainland culture market makes the people and enterprises of Taiwan see the new growth point of cultural development, and hope to transform and upgrade their own cultural industry with the help of this cultural east wind. However, the mainstream media in the island has been linked to culture and politics, which makes the culture of Xiamen and Taiwan constantly encounter various obstacles in the all-round development, which leads to cultural exchanges that can not be carried out in all directions, and has delayed the process of cultural exchange of the Xiamen. 


\section{The widening of the rift between cultural identity}

The development of Xiamen culture continues to develop the path of Chinese traditional culture and keeps the purity of Chinese culture in the process of development. While Taiwan culture is deeply influenced by western culture and Japanese culture in the process of development, it leads to the impure of cultural blood. It further affects the degree of cultural identity between Xiamen and Taiwan, especially among young people. This led to cultural differences in cultural communication and integration, which affected the efficiency of cultural integration.

\section{Geographical factors, colonial culture, partial mentality and other factors}

Because of the inconvenient transportation in the geographical location, Xiamen and Taiwan make the cultural exchanges between the two places inconvenient and can not reach the instantaneous communication, thus increasing the difficulty of communication problems between the two cultures The rule of Holland and Japan, such as the ruling of Taiwan, made the people of Taiwan gradually desalinate the Chinese culture, and then strengthened the local local consciousness. The cultural and ideological system gradually turned from the open to the closed, and the Chinese culture also produced the centrifugal consciousness, which became the restrictive factors of the cultural integration of Xiamen and Taiwan.

\section{ThOUGHTS ON THE StRATEGIC PATH OF XIAMEN CULTURAL INTEGRATION}

The cultural integration of Xiamen and Taiwan can be carried out through four aspects, such as the development of the Taiwan Strait integration, the emotional co construction of the Taiwan youth and the geochemistry of the Taiwan culture, and then the cultural industry, the youth emotion and the culture of Taiwan and Xiamen are well integrated.

\section{A. Build a high-tech innovation culture industry integration mechanism based on the FTA platform, and establish platform guarantee for cultural integration}

The cultural exchange between the two places is difficult to produce a profound fusion effect, to a great extent, the lack of mechanism and platform guarantee, and the setting of the free trade area in Xiamen, to some extent, has solved the problem of mechanism and platform. In the Xiamen free trade area, the Taiwan pavilion has been set up, which is mainly responsible for the introduction of Taiwan cultural enterprises and related talents, formulating long-term planning and short-term planning for cultural integration, and regularly holding corresponding cultural exchanges in the two places. These measures have increased the introduction of cultural talents in Taiwan, improved the efficiency and effect of the integration of high and new technology and culture industry in Xiamen, accelerated the conversion rate of the cultural market in the two places, and greatly promoted the speed and scope of the cultural industry in the two places in Xiamen sea. It has increased the profit rate of cultural enterprises in both places, and promoted Taiwan's cultural industry to link up and merge with Xiamen's cultural industry well. On the basis of the platform of the Xiamen free trade area, the system and system related to the integration of the cultural industry will be accelerated and the policy research and evaluation system related to the integration of the cultural industry and the integration of the cultural industry are accelerated. To increase the overall concentration of the cultural industry, to develop the related industries in the cultural industry chain, to form a number of large cultural backbone enterprises and to cultivate a number of cultural products with the characteristics of the building, clear the orientation of the cultural industry park, and highlight the agglomeration effect of the cultural industry.

\section{B. Strengthen the construction of Xiamen and Taiwan Cultural Industry Park, and promote "five modernization" of cultural exchange between Xiamen and Taiwan}

According to the characteristics of Xiamen culture and the model of the establishment of Cultural Industrial Park, we should adhere to the market oriented model, carry out the allocation of resources through the market, increase the strength of the government leading the development mode of the cultural industrial park, provide a more favorable strategy for the development of cultural industry, and establish the space for the survival and growth of the new small and medium-sized enterprises. We will cultivate a number of cultural export oriented small and medium-sized enterprises, and strengthen the construction of public technology, services, information, financing and trading platforms of regional cultural enterprises.

With the deepening of the exchanges between the two places, the characteristics of the diversification of the field, the high end of the exchange, the brand of activities, the academic exchange, the normalization of the mechanism and the diversity of age. In April 10, 2018, Xiamen officially promulgated some measures to further deepen the economic, social and cultural exchanges and cooperation between Xiamen and Taiwan. The promulgation of this document will help Taiwan compatriots in Xiamen study, entrepreneurship, employment and life to provide the same treatment as Xiamen residents, and promote the better and faster development of Taiwan and capital enterprises in Xiamen.

\section{Strengthen cultural education and exchanges between the two places, enhance the cultural identity of young people in both places and the sense of belonging of Taiwan youth in Xiamen}

The foundation of cultural education and communication is the identification of the root of Chinese culture. In terms of education and communication, specific exchange activities can be carried out for different ages, different cultural levels and different social backgrounds. For primary and middle school students, we can carry out the activities of "Chinese idiom enlightenment", "Chinese classic culture reading", "Chinese cultural words and words" and so on, and carry out spiritual education and edification for children in the island. Full use of cross-strait exchanges and discussions, cultural visits and other activities to show the little drops of cultural life in Xiamen, so that the people of Taiwan in the subtle cohesion of the cultural identity of the two places. We should increase the content of cooperation between Xiamen and Taiwan schools and enhance the frequency of cooperation, expand their cooperation and 
recognize their credits and achievements. Improve the cultural identity of the two people through education.

Based on the exchange of data between Xiamen and Taiwan, through the study of various ways of communication between the young people of the two places, the young people of Xiamen have reached the common fusion of cultural generality, belief and custom, making the young people of Taiwan reach the basis for the exchange of cultural identity between the two sides of the Taiwan Straits. On the basis of the fusion of cultural empathy between Xiamen and Taiwan youth, it will provide suggestions and help for the government to formulate relevant communication decisions. In terms of talent demand, experts and scholars in Taiwan's computer, financial services, cultural and creative, leisure tourism and other fields are the scope of Xiamen's introduction of talents. The government of Xiamen can be more meticulous in formulating policies to enhance the sense of happiness in Taiwan youth in Xiamen and make the young people of the two places a bond of cultural integration.

\section{Promotes the integration of cultural resources in Xiamen and Taiwan, and constructs the development pattern of "two cultural value chains"}

The two regions fully utilize the advanced experience of creative management in Taiwan area to create a duality structure between the cultural exchanges between the two sides of the Taiwan Straits and the practice of modernization. Through this platform, the essence of Chinese traditional culture is excavated and integrated, and its new era features are given, the global value of Chinese culture is highlighted, and the integration and innovation of the two cultures are realized. Both sides break their own limitations, integrate cultural resources, play a chemical effect, use various cultural industry resources flexibly, form two shared brands, expand the influence of regional culture, and enhance the effectiveness of cultural integration. In the use of cultural heritage, historical relics, folk literature, folk culture and other intangible cultural heritage, we can use the cloud technology and regional chain technology to break the inherent information model and construct the cultural value chain which belongs to the two regions, and form a development pattern with two characteristics.

The creation industry of Xiamen and Taiwan has the characteristic of complementarity. Taiwan's wengchuang industry has the characteristics of early start, mature model, perfect management system and high market brand recognition, while the advantages of Xiamen wengchuang industry are mainly embodied in the market scale, rich resources, rich capital, high production efficiency, and many enterprises in the lower and lower reaches. It is these differences that make the cultural industry of Xiamen and Taiwan highly complementary. Therefore, complementary cooperation between the two cultural industries in Xiamen and Taiwan can achieve win-win results for both sides.

\section{E. Research on the communication and integration strategy based on Xiamen and Taiwan Culture}

The geopolitical advantage of Xiamen and Taiwan. Xiamen and Taiwan have good geographical advantages, which have specific interdependence in spatial orientation. Xiamen is only 10 kilometers away from the Golden Gate island and the two mile island, and only 165 nautical miles from Kaohsiung. This unique geographical condition has become the best geographical advantage in the integration of Xiamen and Taiwan culture.

The consanguinity of the two places in Xiamen and Taiwan. The blood relationship between Xiamen and Taiwan is ingrained. Zheng Chenggong resumed Taiwan from Xiamen three hundred and sixty years ago, a large number of Minnan children followed immigrant Taiwan, among which Zhangzhou immigrants were the most immigrants, Quanzhou immigrants were the second, the Xiamen population was mainly composed of Zhangquan immigrants, Xiamen dialect was between the Zhangquan dialect. This blood relationship is the deep foundation for strengthening cultural exchanges between Xiamen and Taiwan.

The marginal advantages of Xiamen and Taiwan. There are similarities in culture, folklore, religion and language between Xiamen and Taiwan. For example, Mazu temple, Thean Hou Temple and so on. The two buildings are very similar to traditional houses and temples in terms of architectural mode, structure, festival customs and eating habits. The rich and generous literary ties between Xiamen and Taiwan have become the driving force for cultural exchanges between the two countries.

The commercial edge between Xiamen and Taiwan. Xiamen and Taiwan have trade in history. Xiamen and Taiwan carry out communication and cooperation in many fields such as textile, food, culture and creativity. In order to promote the complementation of cross-strait industrial exchanges, Xiamen has continuously issued a policy of recruiting talents from Taiwan, introducing various professional talents and attracting many Taiwanese people to come to Xiamen to start a business or to invest in $\mathrm{R} \& \mathrm{D}$. The first comprehensive talent policy issued by the Xiamen zone of the Fujian self trade test area, further highlights the characteristics of the talent for recruiting Taiwan, and has further promoted the discount on the interest rates of venture loans and housing subsidies. Xiamen has launched a number of policies to introduce talents and introduce all kinds of professionals in Taiwan. A number of Taiwan scholars have been introduced in the city of Siming.

The legal edge between Xiamen and Taiwan. Taiwan has been the territory of China since ancient times. Historically, Taiwan is under the jurisdiction of Fujian and has profound legal and political aspects. The profound legal culture of both places provides a profound legal relationship for the cultural exchanges between the two regions.

The traditional customs and customs in Xiamen culture have the same nature, and have a certain geographical and cultural basis for the exchange of grass-roots. At the same time, we can organize more activities, exhibitions and exchanges to promote better communication and integration in the grass- 
roots level of the folk culture in Xiamen. In addition, we can help promote the grass-roots exchanges and enhance the depth of grass-roots exchanges through the integration platform of Xiamen and Taiwan communities.

\section{F. Improving the cross-border e-commerce capability of Xiamen Wen Chuang enterprise}

As the core area of the "one area and one road" strategy, the enterprise can actively participate, enhance the quality of the product and improve the brand effect of the enterprise. With the rapid development of cross-border e-commerce, the opening of China Europe (Xiamen) class, Xiamen cultural enterprises in the export of products to Europe, but also need to speed up the convergence of cultural enterprises, forming a cluster of cultural enterprises with agglomeration, national characteristics and regional characteristics. Under this background, Xiamen and Taiwan should set up the crossborder e-commerce standards as soon as possible while conducting cross-border e-commerce business, and actively butt with the European standards. Secondly, compare the related systems of WTO, relax the entry conditions of the Taiwan funded enterprises, open the open cooperation space, and finally, enrich the products of cross-border e-commerce. Type, accelerate the formation of cultural brand effect.

\section{SUMMARY}

From the perspective of economic development, the integration of Xiamen and Taiwan industry from the perspective of economic development lacks the integration of values and cultural perspectives. Industry convergence is a systematic process. First of all, the concept of industrial integration should form a consensus. Industrial integration is a multi-dimensional concept. It includes technical integration, emotional integration, integration of values, integration of culture in the ground, and community integration to reach the value of Xiamen and the form of economic community. Yes. Therefore, the government must have corresponding strategies to promote and guide the comprehensive integration of the Xiamen industry, change the original single promotion of economic development, lack of a single industrial integration model of cultural identity, and form a complete and sustainable development of the industrial integration and upgrading of the strategy. The combination of similar science and technology, emotion, culture, value and community activities, through the integration of culture to achieve the unity of values, so as to achieve the integration of the industrial integration of the development of the building, and finally, the comprehensive use of identification and measurement of the degree of industrial integration of the industrial integration of the analysis and guidance. Some methods include Beh Finn Dahl index, entropy index method and network analysis method.

\section{ACKNOWLEDGMENT}

Social Sciences Research Program of Education Department of Fujian Province Phased Achievements of "Xiamen and Taiwan Integration Development Research (JAS170778)".

Author introduction: Du Wenchao, male, 1981-03, master of the people of Zhoukou, Henan, lecturer of Xiamen University Tan Kah Kee, the research direction for cultural tourism brand design, brand design, art design, zip code 363105

\section{REFERENCES}

[1] Wang Zhenwei; Xu Chuan. An analysis of the dual segregation structure of cross-strait cultural exchanges $[\mathrm{J}]$. world economic and political forum.2016,9 (5).

[2] Ma Jian. Commentary on the theory of Industrial Convergence: [J]. economics dynamic. 2002,05 .

[3] Li Meiyun. New progress in foreign industrial convergence research [J]. foreign economics and management.2005,12.

[4] Tong Xue Ming. Content and path of cultural integration of knowledge based new immigrants [J]. urban problem.2015,12.

[5] Xie Songfeng; Wei Qiang; realistic challenges and Reflections on crossstrait cultural integration; [J]. modern Taiwan studies.2015,03.

[6] Lei in the field of caring, international vision and synergy spirit analysis of the characteristics of cultural research in Taiwan [J]. Taiwan research quarterly.2014,01

[7] Su Jin Qiang. Deepen grassroots exchanges and consolidate peace development [J]. 2014,01.

[8] unit yuan; Zhao Yulin. Research progress on some theoretical issues of foreign industrial convergence [J]. economic review.2012,05

[9] Wu Huiqiao. The evolution of Qingshui's founder's belief in Taiwan. [J]. Journal of Fuzhou University (PHILOSOPHY AND SOCIAL SCIENCES).2012,01

[10] Zu Qun Ying. Research on the mechanism innovation of cultural exchanges between Fujian and Taiwan at present $[\mathrm{J}]$. Journal of the Party School of Fujian Provincial CPC Committee.2008,4:P90-94.

[11] Shang Guang Yi. Based on the experience of Taiwan, the development strategy of Fujian's cultural industry is discussed. Journal of Fuzhou Party school [J]..2018,1:P40-45

[12] Zhu Dan. Xiamen Taiwan cross border e-commerce logistics mode innovation research based on the free trade zone platform $[\mathrm{J}]$. Journal of Inner Mongolia University of Finance and economics.2018,1:P28-32. 